(C) The Author(s), 2021. Published by Cambridge University Press on behalf of The Nutrition Society. This is an Open Access article, distributed under the terms of the Creative Commons Attribution licence (http://creativecommons.org/licenses/by/4.0/), which permits unrestricted re-use, distribution and reproduction, provided the original article is properly cited

\title{
Influence of geographical latitude on vitamin D status: cross-sectional results from the BiomarCaRE consortium
}

Viktor Oskarsson ${ }^{1 *}$, Mats Eliasson $^{1}$, Veikko Salomaa ${ }^{2}$, Jaakko Reinikainen $^{2}$, Satu Männistö ${ }^{2}$, Luigi Palmieri $^{3}$, Chiara Donfrancesco ${ }^{3}$, Susana Sans ${ }^{4}$, Simona Costanzo ${ }^{5}$, Giovanni de Gaetano ${ }^{5}$, Licia Iacoviello,6, Giovanni Veronesi ${ }^{6}$, Marco M. Ferrario ${ }^{6}$, Teresa Padro $^{7}$, Barbara Thorand ${ }^{8}$, Cornelia Huth ${ }^{8}$, Tanja Zeller ${ }^{9}, 10$, Stefan Blankenberg ${ }^{9,10}$, Annie S. Anderson ${ }^{11}$, Hugh Tunstall-Pedoe ${ }^{12}$, Kari Kuulasmaa ${ }^{2}$, Stefan Söderberg ${ }^{1}$ and on behalf of the BiomarCaRE investigators

${ }^{1}$ Department of Public Health and Clinical Medicine, Umeå University, Umeå 90187, Sweden

${ }^{2}$ Department of Public Health Solutions, Finnish Institute for Health and Welfare, Helsinki, Finland

${ }^{3}$ Department of Cardiovascular, Endocrine-Metabolic Diseases and Aging, Istituto Superiore di Sanità-ISS, Rome, Italy

${ }^{4}$ Catalan Department of Health, Barcelona, Spain

${ }^{5}$ Department of Epidemiology and Prevention, IRCCS Neuromed, Pozzilli, Italy

${ }^{6}$ Department of Medicine and Surgery, University of Insubria, Varese, Italy

${ }^{7}$ Cardiovascular-Program ICCC, Research Institute Hospital Santa Creu i Sant Pau, IIB-Sant Pau, Barcelona, Spain

${ }^{8}$ Institute of Epidemiology, Helmboltz Zentrum München, German Research Center for Environmental Health, Neuherberg, Germany

${ }^{9}$ University Heart and Vascular Center Hamburg, Medical University Hamburg-Eppendorf, Hamburg, Germany

${ }^{10}$ German Center for Cardiovascular Research, Partner Site Hamburg/Lübeck/Kiel, Hamburg, Germany

${ }^{11}$ Centre for Public Health Nutrition Research, University of Dundee, Dundee, Scotland

${ }^{12}$ Institute of Cardiovascular Research, University of Dundee, Dundee, Scotland

(Submitted 9 March 2021 - Final revision received 29 October 2021 - Accepted 14 December 2021 - First published online 22 December 2021)

Abstract

Even though sunlight is viewed as the most important determinant of 25-hydroxyvitamin D (25(OH)D) status, several European studies have observed higher $25(\mathrm{OH}) \mathrm{D}$ concentrations among north-Europeans than south-Europeans. We studied the association between geographical latitude (derived from ecological data) and $25(\mathrm{OH}) \mathrm{D}$ status in six European countries using harmonised immunoassay data from 81084 participants in the Biomarkers for Cardiovascular Risk Assessment in Europe (BiomarCaRE) project (male sex $48.9 \%$; median age 50.8 years; examination period 1984-2014). Quantile regression models, adjusted for age, sex, decade and calendar week of sampling and time from sampling to analysis, were used for between-country comparisons. Up until the median percentile, the ordering of countries by 25(OH)D status (from highest to lowest) was as follows: Sweden (at $65 \cdot 6-63 \cdot 8^{\circ} \mathrm{N}$ ), Germany (at $48 \cdot 4^{\circ} \mathrm{N}$ ), Finland (at $65 \cdot 0-60 \cdot 2^{\circ} \mathrm{N}$ ), Italy $\left(\right.$ at $45 \cdot 6-41 \cdot 5^{\circ} \mathrm{N}$ ), Scotland (at $58 \cdot 2-55 \cdot 1^{\circ} \mathrm{N}$ ) and Spain $\left(\right.$ at $41.5^{\circ} \mathrm{N}$ ). From the 75 th percentile and upwards, Finland had higher values than Germany. As an example, using the Swedish cohort as a comparator, the median 25(OH)D concentration was 3.03, 3.28, 5.41, 6.54 and 9.28 ng/ml lower in the German, Finnish, Italian, Scottish and Spanish cohort, respectively ( $P$-value $<0.001$ for all comparisons). The ordering of countries was highly consistent in subgroup analyses by sex, age, and decade and season of sampling. In conclusion, we confirmed the previous observation of a north-to-south gradient of 25(OH)D status in Europe, with higher percentile values among north-Europeans than south-Europeans.

Key words: Vitamin D: 25-hydroxyvitamin D: Latitude: Epidemiology: Europe: Population based

Vitamin D is a nutrient that has spurred substantial scientific debate over the last 30 years, mostly due to its role in musculoskeletal health ${ }^{(1)}$. In addition, multiple studies have reported on an association between vitamin D status and risk of cancer, cardiac disease, stroke and diabetes (as reviewed by Mondul et al. ${ }^{(2)}$, Rai et $a l^{(3)}$, Zhou et al. ${ }^{(4)}$ and Lips et al. ${ }^{(5)}$, respectively) as well as with

Abbreviations: BiomarCaRE, Biomarkers for Cardiovascular Risk Assessment in Europe; MONICA, Monitoring of Trends and Determinants in Cardiovascular Disease; SHHEC, Scottish Heart Health Extended Cohort; 25(OH)D, 25-hydroxyvitamin D.

* Corresponding author: Dr V. Oskarsson, fax +4690137 633, email viktor.oskarsson@umu.se 
overall mortality (as reviewed by Heath $e t a l .^{(6)}$ ). It is, however, unclear whether these are causal associations, given that randomised clinical trials and other controlled studies have yielded mostly null results ${ }^{(7-10)}$. Recently, it was also hypothesised that vitamin D status might affect the severity of COVID-19(11).

Vitamin D status is defined by the total serum or plasma 25-hydroxyvitamin D (25(OH)D) concentration, of which the two major forms - with equal biological importance are $D_{2}$ (ingested via plant-based or fortified foods) and $D_{3}$ (synthesised in human skin and/or ingested via animal-based or fortified foods $)^{(12)}$. The most important determinant of $25(\mathrm{OH}) \mathrm{D}$ status is thought to be sunlight, which initiates the cutaneous synthesis of $25(\mathrm{OH}) \mathrm{D}^{(13)}$. North-Europeans have, therefore, often been viewed as more at risk for vitamin D insufficiency than other Europeans, mainly because the cutaneous synthesis of $25(\mathrm{OH}) \mathrm{D}$ is virtually undetectable from October to March at geographical latitudes above $50^{\circ} \mathrm{N}^{(14)}$. However, in several European multicentre studies ( $n 824$ to 55844 participants) with harmonised (i.e. analysed in the same lab and with the same assay method) or standardised (i.e. using a Vitamin D Standardisation Program protocol ${ }^{(15)}$ ) data on $25(\mathrm{OH}) \mathrm{D}$, there has been a positive association between geographical latitude and 25(OH)D status ${ }^{(16-23)}$; that is, the opposite of what is naively expected if sunlight is the main determinant of $25(\mathrm{OH}) \mathrm{D}$. The reasons for this are unclear, but it has been suggested that between-country differences in diet (including food-fortification policies) and vitamin D supplement use are contributing factors ${ }^{(21)}$.

Using harmonised data on 25(OH)D from more than 80000 participants in the Biomarkers for Cardiovascular Risk Assessment in Europe (BiomarCaRE) project, we conducted the largest study to date on the association between geographical latitude and 25(OH)D status in Europe.

\section{Subjects and methods}

\section{Study population}

The present study is based on data from the BiomarCaRE project (www.biomarcare.eu) - details of which have been published elsewhere ${ }^{(24)}$ - which, in turn, is based on the Monitoring of Trends and Determinants in Cardiovascular Disease (MONICA) Risk, Genetics, Archiving, and Monograph (MORGAM) project $^{(25,26)}$. The MORGAM/BiomarCaRE Data Centre in Helsinki, Finland, harmonises and stores individual data from a large number of population-based European cohorts, and the BiomarCaRE laboratory in Hamburg (previously in Mainz), Germany, analyses and stores blood samples from several hundred thousand cohort participants.

A total of eight population-based cohorts (including 81084 participants, of whom 3682 were examined more than once) from six European countries (Sweden, Finland, Scotland, Germany, Italy and Spain) had blood samples sent to the BiomarCaRE laboratory for $25(\mathrm{OH}) \mathrm{D}$ measurement and were included in the present study (Online Resource 1). The individual cohorts were: (1) MONICA Northern Sweden (Sweden; examination period 1986, 1990, 1994, 1999 (which also included re-examinations of the surveys in 1986-1994), 2004, 2009 and

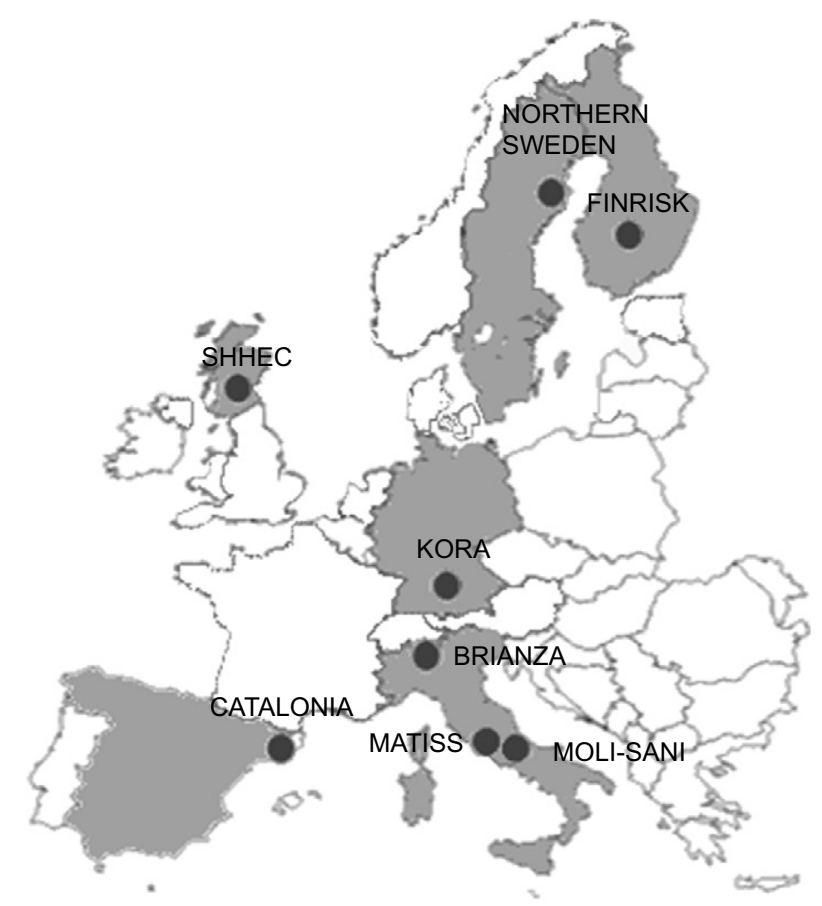

Fig. 1. Approximate geographical location of the included cohorts. SHHEC, Scottish Heart Health Extended Cohort; KORA, Cooperative Health Research in the Region of Augsburg; MATISS, Malattie Aterosclerotiche Istituto Superiore di Sanità.

2014); (2) FINRISK 1997 (Finland; examination period 1997); (3) Scottish Heart Health Extended Cohort (SHHEC) (Scotland; examination period 1984-1987, 1989, 1992 and 1995); (4) MONICA/Cooperative Health Research in the Region of Augsburg (KORA) (Germany; examination period 1994-1995 and 1999-2001); (5) MONICA Brianza (Italy; examination period 1986, 1990 and 1993); (6) Malattie Aterosclerotiche Istituto Superiore di Sanità (Italy; examination period 1993-1996); (7) Moli-sani (Italy; examination period 2005-2010) and (8) MONICA-Catalonia (Spain; examination period 1986-1988 and 1990-1992). Most cohorts examined participants throughout the calendar year (except for the Swedish and Finnish cohort, which examined participants almost exclusively in January to April) and almost all participants were assessed by serum samples (except for $4.4 \%$ in the Swedish cohort, for whom only plasma samples were available). Each cohort was deemed representative of the population of interest (with participation rates ranging from 60 to $81 \%$ ). Further details of the cohorts are presented in Online Resource 2, with their approximate geographical location shown in Fig. 1.

\section{Ethical approval}

This study was conducted according to the guidelines laid down in the Declaration of Helsinki, and all procedures involving human subjects were approved by relevant local ethical review boards. Written informed consent was obtained from all participants. The recommendations of the Strengthening the Reporting of Observational Studies in Epidemiology initiative were followed whenever applicable $\mathrm{e}^{(27)}$. 


\section{Assessment of geographical latitude and other variables}

Data on participant (i.e. sex, age and date of blood sampling) and blood sample characteristics (i.e. type of sampling material (serum or plasma) and date of analysis of 25(OH)D) were obtained from the MORGAM/BiomarCaRE Data Centre in Helsinki, Finland. Data on geographical latitude were based on the location of the largest city in each cohort's recruitment area and retrieved from Google Maps (www.google.com/ maps), except for in the SHHEC where district-level data on geographical latitude were available. For cohorts that had recruited participants over a large geographical area (i.e. MONICA Northern Sweden, FINRISK 1997 and SHHEC), the participants were classified into subcohorts according to the recruitment area or district area. The estimated geographical latitudes for the included cohorts are presented in detail in Online Resource 3. In brief, along a north-to-south axis, the following geographical latitudes were applied for each country: Sweden $\left(65.6-63.8^{\circ} \mathrm{N}\right)$, Finland $\left(65 \cdot 0-60 \cdot 2^{\circ} \mathrm{N}\right)$, Scotland $\left(58 \cdot 2-55 \cdot 1^{\circ} \mathrm{N}\right)$, Germany $\left(48 \cdot 4^{\circ}\right.$ $\mathrm{N})$, Italy $\left(45 \cdot 6-41 \cdot 5^{\circ} \mathrm{N}\right)$ and Spain $\left(41 \cdot 5^{\circ} \mathrm{N}\right)$.

\section{Assessment of 25-hydroxyvitamin D status}

Serum or plasma analyses of $25(\mathrm{OH}) \mathrm{D}$ were conducted between 2009 and 2018 at the BiomarCaRE laboratory in Germany (located in Mainz up until 2012, thereafter in Hamburg) using a 1-step immunoassay on the Abbott ARCHITECT i2000 (Abbott Diagnostics) $^{(28)}$. Previous research has shown that serum and plasma measurements of 25(OH)D are highly similar ${ }^{(29)}$. The cohort-specific years of analysis and intra-assay and inter-assay coefficients of variation are shown in Online Resource 4. No evidence of laboratory drift was observed during the study period (data not shown).

In a subgroup of the MONICA Northern Sweden cohort ( $n$ 1522), the 25(OH)D status estimated from the Abbott ARCHITECT has been compared with that estimated from a HPLC-MS/MS (traceable to the National Institute of Standards and Technology's Standard Reference Material 972) ${ }^{(30,31)}$, which is considered a more accurate method for $25(\mathrm{OH}) \mathrm{D}$ analyses ${ }^{(32)}$. Although the measurement methods had a good correlation in terms of rank (Spearman's coefficient $(r)=0 \cdot 82-0 \cdot 91$, irrespective of sex and age group), the $25(\mathrm{OH}) \mathrm{D}$ concentrations were on average $8.4 \mathrm{ng} / \mathrm{ml}$ lower when measured with the Abbott ARCHITECT

\section{Statistical analysis}

A total of 81084 participants and 84766 blood samples were included for analysis. Data on 25(OH)D status were missing for 3832 blood samples ( $4.5 \%$, ranging from $1.0 \%$ in the Swedish cohort to $11.3 \%$ in the Scottish cohort). The main reasons for missing data were too small blood sample volumes (for the Scottish, German, Italian and Spanish cohorts) and technical issues during the laboratory procedure (for the Swedish and Finnish cohort). (See Online Resource 4 for cohort-specific percentages of missing data and reasons for missing data.) Missing data were handled using multiple imputation by chained equations (10 data sets were created and combined using Rubin's rule $)^{(33)}$, in which sex, age, calendar year of sampling, calendar week of sampling, type of sampling material and cohort were included as regular variables. There was no evidence of violation of the missing at random assumption (data not shown). In a sensitivity analysis, we repeated the analyses using complete case data.

To study the exposure-outcome association in detail, we used quantile regression models and calculated percentile values (1st99th) of $25(\mathrm{OH}) \mathrm{D}$ status according to country (ordered by decreasing geographical latitude: Sweden (comparator), Finland, Scotland, Germany, Italy and Spain) and geographical latitude (continuous, ${ }^{\circ} \mathrm{N}$ ). Geographical latitude was modelled as a continuous variable assuming linearity (i.e. a constant change in $25(\mathrm{OH}) \mathrm{D}$ concentration for each unit of change in geographical latitude). To relax this assumption, we used 4-knot restricted cubic splines in a continuous analysis (knots at $65 \cdot 0,55 \cdot 8,48 \cdot 4$ and $\left.41 \cdot 6^{\circ} \mathrm{N}\right)^{(34)}$ and also performed a separate categorical analysis (using the northernmost subcohort (at $65 \cdot 6^{\circ} \mathrm{N}$ ) as comparator). A test for non-linearity in the restricted cubic spline model was conducted by testing the coefficients of the second and third spline transformation jointly equal to zero. In a sensitivity analysis, we repeated the analyses using mean regression models.

Multivariable quantile regression models were adjusted for sex, age (continuous, years), decade of sampling (1980s, 1990s, 2000s), calendar week of sampling (continuous, calendar weeks) and time from sampling to analysis (continuous, years). Since there was evidence of non-linear associations between $25(\mathrm{OH}) \mathrm{D}$ status and age (inverse J curve), calendar week of sampling (seasonal curve, as shown in Online Resource 5) and time from sampling to analysis (right-tilted L curve), we modelled these covariates using 4-knot restricted cubic splines (knots at the 5th, 35th, 65th and 95th percentile). Varying the number of knots (to 3 or 5 knots) had negligible influence on the results (data not shown).

Separate quantile regression models by (1) sex, (2) age $(<51$ (median), $\geq 51$ years), (3) decade of sampling (1980s, 1990s, 2000s) and (4) season of sampling (winter (December to February), spring (March to May), summer (June to August), fall (September to November)) were performed as subgroup analyses. Since a proportion of the Swedish cohort had been examined more than once (treated as independent observations in the main analysis; $n$ 3682) and/or with plasma instead of serum ( $n$ 687), we also performed a sensitivity analysis by restricting the quantile regression model to first-time serum blood samples ( $n$ 80 397).

Statistical significance was set at a two-sided $P$-value less than 0.05. Analyses were performed using Stata version 14 (StataCorp LP).

\section{Results}

A total of 81084 participants ( $48.9 \%$ men; median age 50.8 years), who contributed with 84766 blood samples during the 1980s (21.8\%), 1990s (39.5\%) and 2000s (38.8\%), were included for analysis. Forty point two percentage were from Italy ( $n$ 32 572), 18.4\% from Scotland ( $n 14$ 902), 14.8\% from Sweden ( $n 11973$, of whom 3682 had been examined more than once), $10.4 \%$ from Germany ( $n$ 8393), $9.9 \%$ from Finland 
Table 1. Baseline characteristics of the study population ( $n 81084$, including 84766 observations) by country (Percentages unless otherwise specified)

\begin{tabular}{|c|c|c|c|c|c|c|}
\hline & \multicolumn{6}{|c|}{ Country (ordered by decreasing geographical latitude) } \\
\hline & Sweden & Finland & Scotland & Germany & Italy* & Spain \\
\hline No. of participants & 11973 & 8002 & 14902 & 8393 & 32572 & 5242 \\
\hline \multicolumn{7}{|l|}{$\begin{array}{l}\text { Participant characteristics } † \\
\text { Age (vears) }\end{array}$} \\
\hline Median & $51 \cdot 2$ & 48.4 & $49 \cdot 8$ & $50 \cdot 2$ & $53 \cdot 1$ & $45 \cdot 7$ \\
\hline Range & $24 \cdot 1,79 \cdot 3$ & $24 \cdot 2,74 \cdot 3$ & $25 \cdot 2,75 \cdot 8$ & $24 \cdot 6,75 \cdot 5$ & $20 \cdot 6,98 \cdot 7$ & $24 \cdot 8,67 \cdot 8$ \\
\hline Male sex & $49 \cdot 1$ & $50 \cdot 0$ & $50 \cdot 2$ & $49 \cdot 7$ & $46 \cdot 8$ & 54.3 \\
\hline \multicolumn{7}{|l|}{ Decade of sampling } \\
\hline $1980 \mathrm{~s}$ & $10 \cdot 2$ & - & 77.9 & - & 8.5 & $47 \cdot 0$ \\
\hline 1990s & 57.9 & 100 & $22 \cdot 1$ & $57 \cdot 1$ & $17 \cdot 0$ & $53 \cdot 0$ \\
\hline $2000 s$ & 31.9 & - & - & $42 \cdot 9$ & 74.5 & - \\
\hline \multicolumn{7}{|l|}{ Season of sampling } \\
\hline Winter (December to February) & $52 \cdot 9$ & $55 \cdot 6$ & $15 \cdot 6$ & $32 \cdot 1$ & $22 \cdot 9$ & $22 \cdot 2$ \\
\hline Spring (March to May) & $47 \cdot 1$ & 44.4 & $33 \cdot 3$ & $31 \cdot 1$ & $28 \cdot 7$ & 29.4 \\
\hline Summer (June to August)‡ & - & - & $27 \cdot 6$ & $8 \cdot 6$ & $19 \cdot 8$ & $18 \cdot 1$ \\
\hline Fall (September to November) & - & - & $23 \cdot 5$ & $28 \cdot 2$ & $28 \cdot 6$ & $30 \cdot 3$ \\
\hline \multicolumn{7}{|l|}{ Blood sample characteristics $\dagger$} \\
\hline \multicolumn{7}{|l|}{ Time to analysis (years) } \\
\hline Median & $18 \cdot 3$ & $15 \cdot 9$ & $24 \cdot 3$ & $19 \cdot 8$ & $7 \cdot 7$ & $25 \cdot 7$ \\
\hline Range & $3.5,30.8$ & $15 \cdot 3,16 \cdot 1$ & $15 \cdot 9,27 \cdot 2$ & $13 \cdot 9,20 \cdot 6$ & $4.5,28 \cdot 8$ & $24 \cdot 1,30 \cdot 3$ \\
\hline \multicolumn{7}{|l|}{ Type of sampling material } \\
\hline Serum & 95.6 & 100 & 100 & 100 & 100 & 100 \\
\hline Plasma & 4.4 & - & - & - & - & - \\
\hline
\end{tabular}

* The Italian study population was recruited from three separate cohorts, for which details are given in Online Resource 6.

$\dagger$ Based on the total number of observations in each cohort (3682 participants in the Swedish cohort were examined more than once, leading to a total of 15655 observations). $\ddagger$ Three participants in the Swedish cohort and one participant in the Finnish cohort were sampled in summer or fall.

( $n$ 8002) and $6.5 \%$ from Spain ( $n$ 5242). Blood samples were more often drawn in winter (December to February; $31.3 \%$ ) and spring (March to May; $34.7 \%$ ) than in summer (June to August; $14.4 \%$ ) and fall (September to November; $19.8 \%$ ).

Participant and blood sample characteristics by country are shown in Table 1. (Nota bene: the Italian study population was recruited from three separate cohorts, for which details are given in Online Resource 6.) Apart from the Italian and Spanish cohort (with the largest and smallest percentage of women $(53.2 v .45 .7 \%)$ and the highest and lowest median age (53.1 v. 45.7 years), respectively), the cohorts' sex and median age structures were quite homogenous (female sex $49 \cdot 8-50.9 \%$; median age $48 \cdot 4-50 \cdot 2$ years). In contrast, there was a large between-cohort difference in the time period of sampling and, subsequently, in the time from sampling to analysis (as an example, the overwhelming majority of Scottish and Italian participants were sampled in the 1980s and 2000s, respectively, while all Finnish participants were sampled in the 1990s). Most cohorts had sampled participants throughout the calendar year, except for the Swedish and Finnish cohort, which had sampled participants almost exclusively in winter and spring. A small percentage of Swedish participants had been sampled with plasma instead of serum.

The median 25(OH)D concentration was $16.4 \mathrm{ng} / \mathrm{ml}$ in the entire study population, $15.5 \mathrm{ng} / \mathrm{ml}$ in the female population and $17.3 \mathrm{ng} / \mathrm{ml}$ in the male population. As expected, there was a strong seasonal variation of $25(\mathrm{OH}) \mathrm{D}$ status (Fig. 2). In cohorts that had sampled participants throughout the calendar year, the highest and lowest median concentrations were observed in August to September and February to March, respectively, with an absolute (relative) peak-to-minimum variation of $10.7 \mathrm{ng} / \mathrm{ml}(96 \%)$ in
Scotland, $14.7 \mathrm{ng} / \mathrm{ml}(110 \%)$ in Germany, $13.9 \mathrm{ng} / \mathrm{ml}(110 \%)$ in Italy and $11.6 \mathrm{ng} / \mathrm{ml}(122 \%)$ in Spain. The difference in $25(\mathrm{OH})$ D status according to the decade of sampling is presented in Online Resource 7 . There were indications of higher 25(OH)D concentrations over time, with an absolute (relative) 2000s-to-1980s variation of $1.4 \mathrm{ng} / \mathrm{ml}$ (10\%) during winter, $2.0 \mathrm{ng} / \mathrm{ml}(16 \%)$ during spring, $3 \cdot 1 \mathrm{ng} / \mathrm{ml}(17 \%)$ during summer and $5.4 \mathrm{ng} / \mathrm{ml}$ (31\%) during fall.

Unadjusted percentile values of $25(\mathrm{OH}) \mathrm{D}$ status by country are shown in Fig. 3. In the multivariable model, the ordering of countries by $25(\mathrm{OH}) \mathrm{D}$ status (from highest to lowest) was as follows up until the median percentile: Sweden (at $65 \cdot 6-63 \cdot 8^{\circ} \mathrm{N}$ ), Germany (at $48 \cdot 4^{\circ} \mathrm{N}$ ), Finland (at $65 \cdot 0-60 \cdot 2^{\circ} \mathrm{N}$ ), Italy (at $45 \cdot 6-41 \cdot 5^{\circ} \mathrm{N}$ ), Scotland (at $58 \cdot 2-55 \cdot 1^{\circ} \mathrm{N}$ ) and Spain (at $41 \cdot 5^{\circ} \mathrm{N}$ ) (Table 2). From the 75 th percentile and upwards, the Finnish cohort had higher values than the German cohort. As an example, using the Swedish cohort as comparator, the median (25th, 75th percentile) $25(\mathrm{OH}) \mathrm{D}$ concentration was $3.03(2.36,3.75) \mathrm{ng} / \mathrm{ml}$ lower in the German cohort, $3.28(2.96,3.48) \mathrm{ng} / \mathrm{ml}$ lower in the Finnish cohort, $5.41(4.61,6.17) \mathrm{ng} / \mathrm{ml}$ lower in the Italian cohort, 6.54 $(5 \cdot 27,7.49) \mathrm{ng} / \mathrm{ml}$ lower in the Scottish cohort and 9.28 (7.65, $10.59) \mathrm{ng} / \mathrm{ml}$ lower in the Spanish cohort $(P$-value $<0.001$ for all comparisons). The ordering of countries was highly consistent, although with some between-country differences in the magnitude of the exposure-outcome association, in subgroup analyses by sex, age, and decade and season of sampling (Table 3). Likewise, the results were similar in the sensitivity analysis restricted to first-time serum blood samples (median difference (ng/ml) compared with Sweden: Germany $-2 \cdot 73$, Finland $-2 \cdot 32$, Italy $-5 \cdot 16$, Scotland $-6 \cdot 12$ and Spain $-9 \cdot 23$; $P$-value $<0.001$ for all comparisons) and in the sensitivity analysis based 


\section{Sweden}
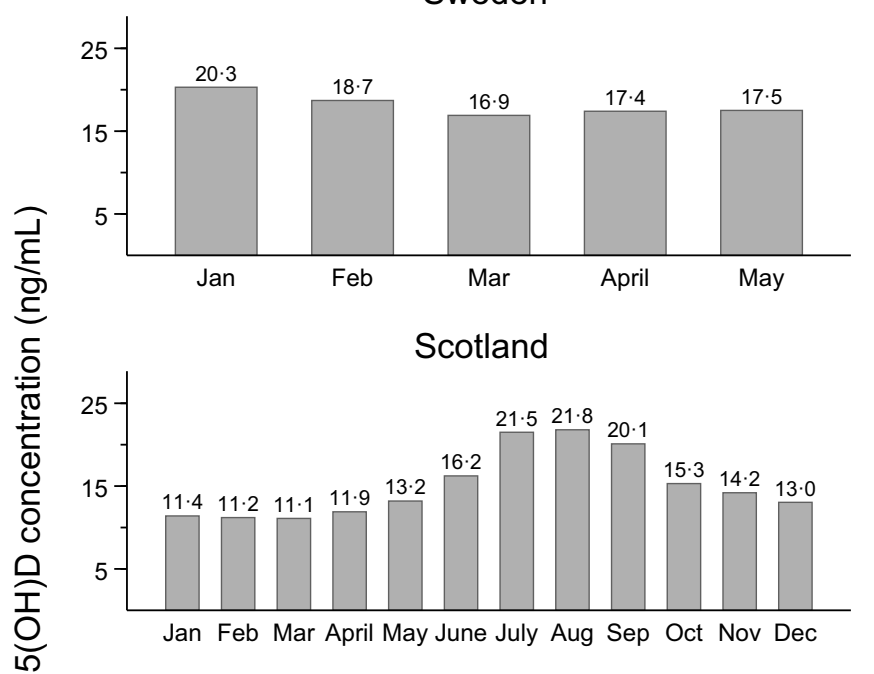
of the results did not change in the sensitivity analysis using mean regression (data not shown).

In the analysis of geographical latitude as a continuous variable, there was a positive association between geographical latitude and 25(OH)D status (median increase of $0.23 \mathrm{ng} / \mathrm{ml}$ for each 1-unit increase in geographical latitude (95\% CI $0 \cdot 22,0 \cdot 24 ; P$-value $<0 \cdot 001)$ ). However, as shown in Fig. 4 , this linear dose-response model captured the shape of the exposure-outcome association very poorly compared with the restricted cubic spline model $(P$-value $<0.001$ for nonlinearity) and, especially, the categorical model. In countries with multiple recruitment areas, the within-country median difference in $25(\mathrm{OH}) \mathrm{D}$ concentration ranged from $0.35 \mathrm{ng} / \mathrm{ml}$ in Sweden to $2 \cdot 81 \mathrm{ng} / \mathrm{ml}$ in Finland (based on the categorical exposure model).

\section{Discussion}

In this cross-sectional study, which included more than 80000 participants from six European countries, we observed a northto-south gradient of $25(\mathrm{OH}) \mathrm{D}$ status (although not linear in its shape), with higher percentile values in the northernmost countries (i.e. Sweden and Finland) compared with the southernmost (Sabadell). (Information on day length was derived from www.timeanddate.com).
Finland

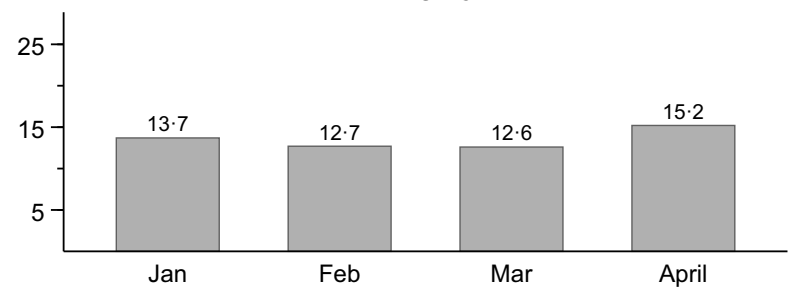

Germany
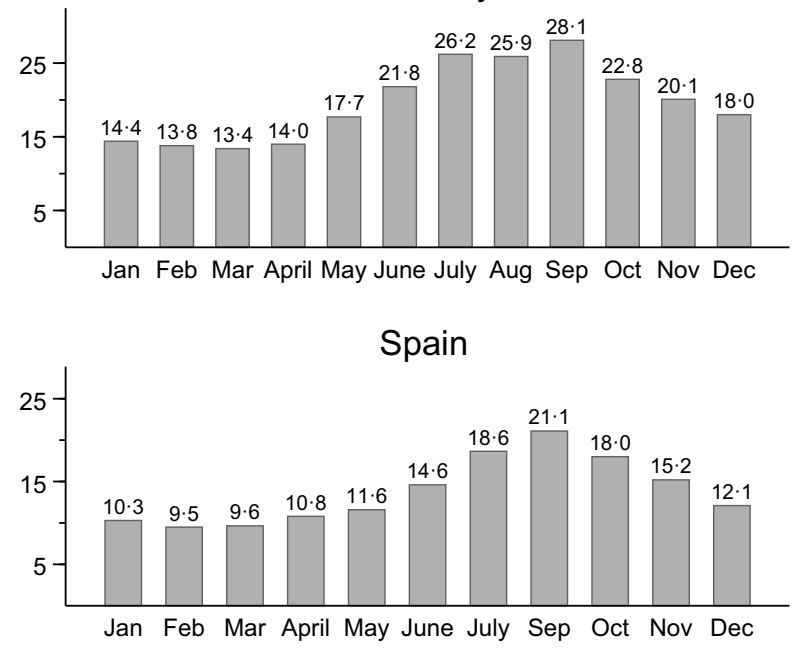

Fig. 2. Observed monthly variation of 25 -hydroxyvitamin $\mathrm{D}(25(\mathrm{OH}) \mathrm{D})$ status in the study population with complete data on $25(\mathrm{OH}) \mathrm{D}(\mathrm{n} 77320$, including 80934 obser(Helsinki), 7:05 and 17:30 h in Scotland (Edinburgh), 8:24 and 16:02 h in Germany (Augsburg), 8:46 and 15:38 h in Italy (Monza), and 9:15 and 15:07 h in Spain

countries (i.e. Spain and Italy). These findings were highly consistent in subgroup analyses by sex, age, and decade and season of sampling.

Several other studies with harmonised or standardised data on $25(\mathrm{OH}) \mathrm{D}$ have reported on a north-to-south gradient in Europe $^{(16-23)}$. In the EURONUT-SENECA study ( $n$ 824), men and women from Norway and Denmark had higher mean concentrations of $25(\mathrm{OH}) \mathrm{D}$ than their counterparts in Spain and Italy ${ }^{(16)}$. Similar findings were observed in three randomised clinical trials of postmenopausal women ( $n$ 997-3195), where the mean concentrations of $25(\mathrm{OH}) \mathrm{D}$ were higher in northern Europe than in southern Europe ${ }^{(17-19)}$. Deleskog et al. also reported on a positive association between geographical latitude and $25(\mathrm{OH}) \mathrm{D}$ status in a cohort of 3430 European men and women $^{(20)}$. In the ODIN project, which combined and standardised $25(\mathrm{OH}) \mathrm{D}$ data from eighteen European studies ( $n$ 55 844), the mean concentrations of $25(\mathrm{OH}) \mathrm{D}$ were higher in Norway and Iceland - but slightly lower in Finland - compared with Greece ${ }^{(21)}$. Likewise, the mean concentrations of $25(\mathrm{OH}) \mathrm{D}$ were higher in Norwegian participants than in south-European participants in the European Eye study $(n \text { 4495 })^{(22)}$. Finally, in the European Prospective Investigation into Cancer and Nutrition-Interact case-cohort study ( $n 22$ 651), the authors observed a positive association between geographical latitude and 25(OH)D status ${ }^{(23)}$. 
December to February

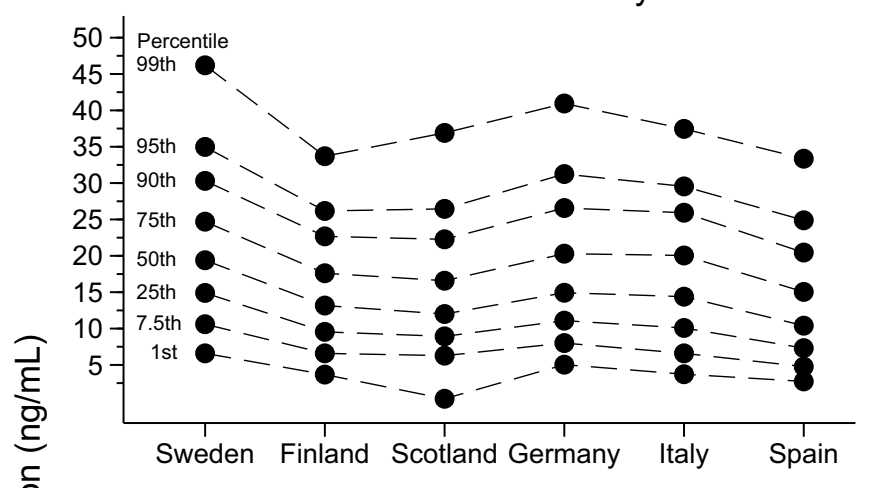

June to August

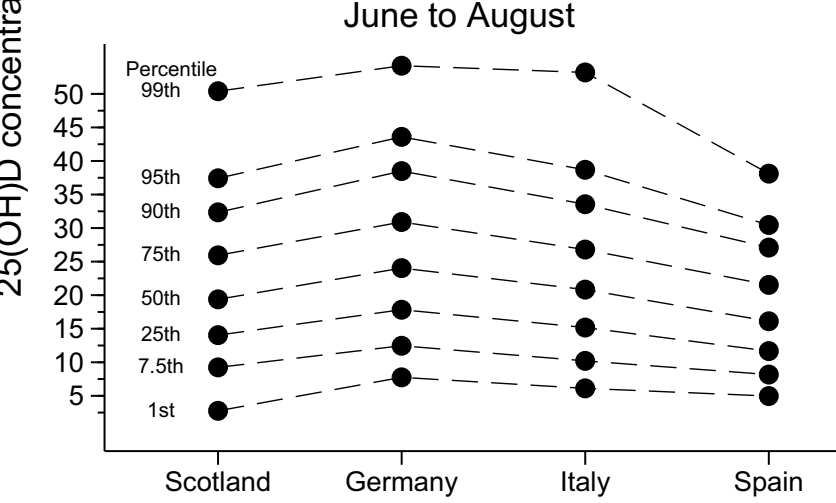

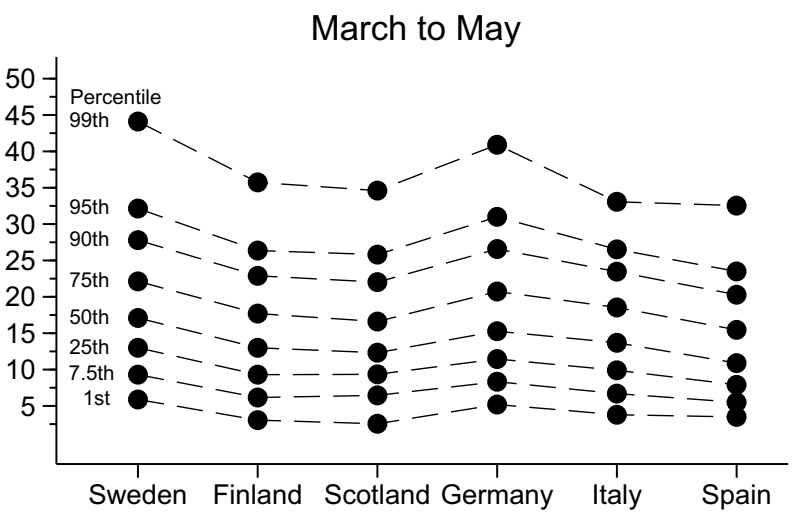

September to November

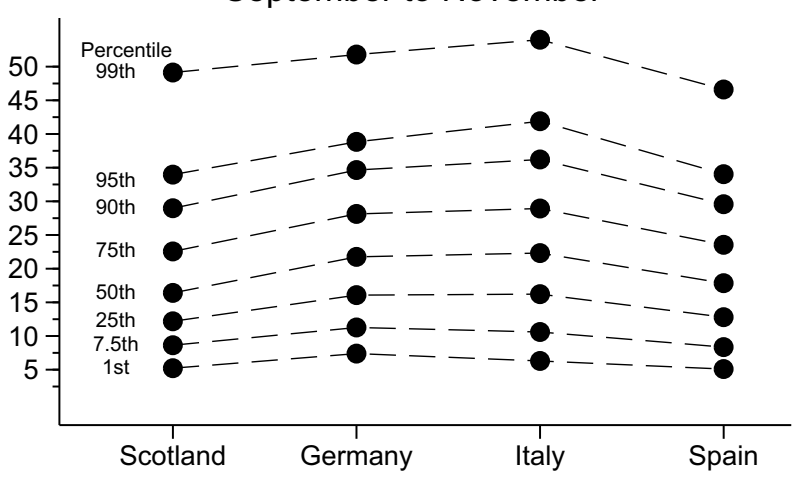

Fig. 3. Percentile distribution of 25 -hydroxyvitamin $\mathrm{D}(25(\mathrm{OH}) \mathrm{D})$ status in the study population ( $n 81084$, including 84766 observations) by country (ordered by decreasing geographical latitude) and season of sampling (winter, spring, summer and fall) and based on multiple imputed data sets ( $n 10)$. The solid dots represent unadjusted percentile values for each country. The dashed lines are added to facilitate between-country comparisons of each percentile.

Sunlight is an important determinant of $25(\mathrm{OH}) \mathrm{D}$ status, as exemplified by the strong seasonal variation in our data (the median concentration in the pooled population was $9.8 \mathrm{ng} / \mathrm{ml}$ lower in March than in August and September). However, based on the available literature of a north-to-south gradient, it is questionable if sunlight should be viewed as the most important determinant of 25(OH)D status in today's society ${ }^{(13)}$, at least from a European perspective. In analogy, it may not be correct to view north-European populations as more at risk for vitamin D insufficiency than other European populations, despite the fact that the cutaneous synthesis of $25(\mathrm{OH}) \mathrm{D}$ is virtually undetectable during winter at geographical latitudes above $50^{\circ} \mathrm{N}^{(14)}$.

Other factors that have a large influence on $25(\mathrm{OH}) \mathrm{D}$ status are the consumption of vitamin D-rich food items (e.g. fatty fish and shellfish) and vitamin D-fortified food items (e.g. milk and margarine) as well as the use of vitamin D-containing supplements ${ }^{(13)}$. In the European Prospective Investigation into Cancer and Nutrition calibration study, which used a standardised FFQ and was based on data from 1995 to 2000 ( $n 36$ 034), it was observed that north-Europeans had a higher food intake of vitamin D than south-Europeans ${ }^{(35)}$. The highest intakes were seen in the Swedish participants, most likely due to Sweden's long tradition of voluntary - and since 2007 mandatory - vitamin D fortification of milk, margarine and cooking fats ${ }^{(30)}$.
Interestingly enough, given that the Swedish cohort already had the highest $25(\mathrm{OH}) \mathrm{D}$ concentrations in our data, the vitamin D food-fortification policy in Sweden was expanded in 2018, so that it now includes more food items and dictates a higher quantity of vitamin D in each food item (Swedish National Food Agency, personal communication, 2019). At the time when the Finnish cohort was examined (1997), the Finnish legislation only allowed for voluntary vitamin D fortification of certain milk and margarine products by permission (Finnish Food Authority, personal communication, 2020). Since then, the Finnish Food Authority has started to recommend vitamin D fortification of all milk and margarine products, to which most companies have complied and that has led to increased $25(\mathrm{OH}) \mathrm{D}$ concentrations in the Finnish population ${ }^{(36)}$. In the other countries that were included in our study, vitamin D-fortified products are commercially available, but its consumption is not specifically advised and there are no mandatory food-fortification policies (with the exception of margarine products in Scotland) ${ }^{(37)}$. With respect to supplement use, it was observed in the previously mentioned European Prospective Investigation into Cancer and Nutrition calibration study that Swedish participants used supplements four to five times as often as Italian and Spanish participants ${ }^{(38)}$. The Swedish participants were also more likely to use supplements that contained vitamin D. A potential 
increase in the use of vitamin D supplements in Europe over time (as noted in the $\mathrm{USA}^{(39)}$ ) could, in turn, be a partial explanation to the seemingly higher $25(\mathrm{OH}) \mathrm{D}$ concentrations in the $2000 \mathrm{~s} \mathrm{com-}$ pared with the 1980s in our data.

In addition to a large sample size that was recruited from six European countries (with geographical latitudes ranging from 65.6 to $41 \cdot 5^{\circ} \mathrm{N}$ ), the main strength of the current study was the use of harmonised data on $25(\mathrm{OH}) \mathrm{D}$ (i.e. analysed in the same lab and with the same assay method). As often discussed in the past, comparative studies on $25(\mathrm{OH}) \mathrm{D}$ status can be severely hampered by variations in assay method ${ }^{(40-42)}$. Other strengths were the use of multiple percentile values to fully describe the exposure-outcome association as well as the fact that blood metabolites of 25(OH)D have been shown to be robust to handling $^{(43)}$, storage duration ${ }^{(44)}$ and multiple freeze-thaw cycles ${ }^{(45)}$.

A number of limitations of the current study must be mentioned. Firstly, we had no individual data on geographical latitude and instead used an ecological assignment (i.e. the geographical latitude of the largest city in each recruitment area, except for in the SHHEC where district-level data were available). While the ecological assignment did not affect the between-country comparisons, it led to clustering of participants within recruitment areas and hindered a more detailed analysis of geographical latitude as a continuous variable. Secondly, we used geographical latitude as a proxy for sunlight incidence, assuming a direct correlation between geographical latitude and the hours and quality of sunlight. It is, however, possible that the months preceding the blood sampling could have had unusually many (or few) total hours of sunlight in a specific region, which, in turn, could have affected the within-country comparisons and the between-country comparisons for recruitment areas located close to each other (i.e. Sweden $v$. Finland and Italy $v$. Spain). With that said, it is unlikely that local weather deviations should have had a big impact on the more extreme comparisons, such as Sweden (at $65 \cdot 6-63.8^{\circ} \mathrm{N}$ ) compared with Spain (at $41.5^{\circ} \mathrm{N}$ ). In addition, we had no data on the participants' sun behaviour (e.g. actual time spent in the sunlight, avoidance of sunlight during the warmest hours and type of clothing used in the sunlight), which is likely to have differed between countries. Thirdly, the data on 25(OH)D status in the Swedish and Finnish cohorts were restricted to participants sampled in winter and spring. As consequence, we had to assume in the statistical model that the seasonal variation of $25(\mathrm{OH}) \mathrm{D}$ status was the same in all countries, which, based on the observed data (where the country-specific seasonal variation ranged from $10 \cdot 7$ to $14 \cdot 7$ $\mathrm{ng} / \mathrm{ml}$ ), might have skewed the multivariable-adjusted estimates to a certain degree. However, the relative seasonal variation in the Swedish cohort had had to be less than $66 \%$ (median value) and $60 \%$ (mean value) in order to not be ranked first in peak $25(\mathrm{OH}) \mathrm{D}$ status, which is lower than the seasonal variation recently reported in a Swedish study (mean variation of $73 \%$ between February and July) ${ }^{(46)}$. A proportion of the Swedish participants had also been sampled more than once (and treated as independent observations), leading to potential bias in the quantile regression model. However, the results were highly similar in the sensitivity analysis restricted to first-time blood samples. Fourthly, there was a rather large variability in the betweencohort percentages of missing $25(\mathrm{OH}) \mathrm{D}$ data (ranging from 
Table 3. Subgroup analyses of differences in $25(\mathrm{OH}) \mathrm{D}$ status in the study population ( $n 81084$, including 84766 observations) by country and based on multiple imputed data sets (n 10)

\begin{tabular}{|c|c|c|c|c|c|c|c|c|c|c|c|c|}
\hline \multirow[b]{3}{*}{$25(\mathrm{OH}) \mathrm{D}$ status $(\mathrm{ng} / \mathrm{ml})$} & \multicolumn{12}{|c|}{ Country (ordered by decreasing geographical latitude) } \\
\hline & \multicolumn{2}{|c|}{ Sweden } & \multicolumn{2}{|c|}{ Finland } & \multicolumn{2}{|c|}{ Scotland } & \multicolumn{2}{|c|}{ Germany } & \multicolumn{2}{|c|}{ Italy } & \multicolumn{2}{|c|}{ Spain } \\
\hline & $\begin{array}{c}\text { Median } \\
\text { difference }^{*}\end{array}$ & $95 \% \mathrm{Cl}$ & $\begin{array}{c}\text { Median } \\
\text { difference }^{*}\end{array}$ & $95 \% \mathrm{Cl}$ & $\begin{array}{c}\text { Median } \\
\text { difference }^{*}\end{array}$ & $95 \% \mathrm{Cl}$ & $\begin{array}{c}\text { Median } \\
\text { difference }^{*}\end{array}$ & $95 \% \mathrm{Cl}$ & $\begin{array}{c}\text { Median } \\
\text { difference }\end{array}$ & $95 \% \mathrm{Cl}$ & $\begin{array}{c}\text { Median } \\
\text { difference }^{*}\end{array}$ & $95 \% \mathrm{Cl}$ \\
\hline \multicolumn{13}{|l|}{ By sex } \\
\hline Men & Comp. & - & $-2 \cdot 22$ & $-2 \cdot 74,-1 \cdot 70$ & -5.65 & $-6.09,-5.20$ & $-2 \cdot 11$ & $-2.53,-1.69$ & -3.59 & $-3 \cdot 89,-3 \cdot 28$ & -8.46 & $-9.06,-8.23$ \\
\hline Women & Comp. & - & -4.23 & $-4 \cdot 73,-3 \cdot 74$ & -7.37 & $-7.78,-6.96$ & -4.04 & $-4.44,-3.64$ & -6.90 & $-7 \cdot 19,-6 \cdot 60$ & -9.87 & $-10 \cdot 27,-9.47$ \\
\hline \multicolumn{13}{|l|}{ By median age } \\
\hline$<51$ years & Comp. & - & -3.5 & $-4.02,-3.08$ & -5.77 & $-6 \cdot 19,-5 \cdot 36$ & -1.59 & $-1.99,-1.18$ & -3.46 & $-3 \cdot 76,-3 \cdot 15$ & -8.37 & $-8.73,-8.01$ \\
\hline$\geq 51$ years & Comp. & - & -1.94 & $-2.44,-1.43$ & -6.80 & $-7 \cdot 22,-6 \cdot 38$ & -4.38 & $-4.75,-4.01$ & -7.33 & $-7.61,-7.06$ & -10.09 & $-10.49,-9.68$ \\
\hline \multicolumn{13}{|l|}{ By decade of sampling } \\
\hline $1980 \mathrm{~s}$ & Comp. & - & - & - & -6.43 & $-6.91,-5.94$ & - & - & -3.71 & $-4.37,-3.06$ & -7.65 & $-8 \cdot 20,-7 \cdot 10$ \\
\hline $1990 \mathrm{~s}$ & Comp. & - & -5.44 & $-5 \cdot 70,-5 \cdot 19$ & -7.05 & $-7.45,-6.64$ & $-5 \cdot 19$ & $-5.54,-4.85$ & -6.67 & $-7.02,-6.32$ & -9.07 & $-9.42,-8.72$ \\
\hline $2000 \mathrm{~s}$ & Comp. & - & - & - & - & - & -2.57 & $-2 \cdot 96,-2 \cdot 18$ & -3.92 & $-4 \cdot 20,-3 \cdot 64$ & - & - \\
\hline \multicolumn{13}{|c|}{ By season of samplingt,‡ } \\
\hline Winter & 7.77 & $7 \cdot 20,8.35$ & 2.77 & $1.89,3.65$ & Comp. & - & 3.67 & $3.09,4.25$ & 1.55 & $0.96,2 \cdot 14$ & -2.06 & $-2 \cdot 76,-1 \cdot 36$ \\
\hline Spring & 4.95 & $4.58,5.32$ & $2 \cdot 91$ & $2.33,3.50$ & Comp. & - & 2.89 & $2.38,3.40$ & 0.50 & $0.11,0.88$ & -2.58 & $-3 \cdot 05,-2 \cdot 11$ \\
\hline Summer & - & - & - & - & Comp. & - & 5.18 & $3.65,6.72$ & 0.31 & $-0.40,1.03$ & -2.52 & $-3.59,-1.44$ \\
\hline Fall & - & - & - & - & Comp. & - & 6.73 & $5.91,7.56$ & 3.75 & $3.02,4.49$ & -3.25 & $-4 \cdot 40,-2 \cdot 10$ \\
\hline
\end{tabular}

25(OH)D, 25-hydroxyvitamin D; Comp., comparator.

* Estimated from quantile regression models adjusted for sex, age (continuous using 4-knot restricted cubic splines (4-RCS), years), calendar week of sampling (continuous using 4-RCS, calendar weeks), decade of sampling (1980s, 1990s, 2000s) and time from sampling to analysis (continuous using 4-RCS, years).

t Only three participants in the Swedish cohor and one participant in the Finnish cohort were sampled in summer or fall; therefore, to facilitate between-country comparisons across all subgroups, Scotland was used as the comparator group. ‡ Adjusted for the 3 months in each season of sampling (as a categorical variable). 


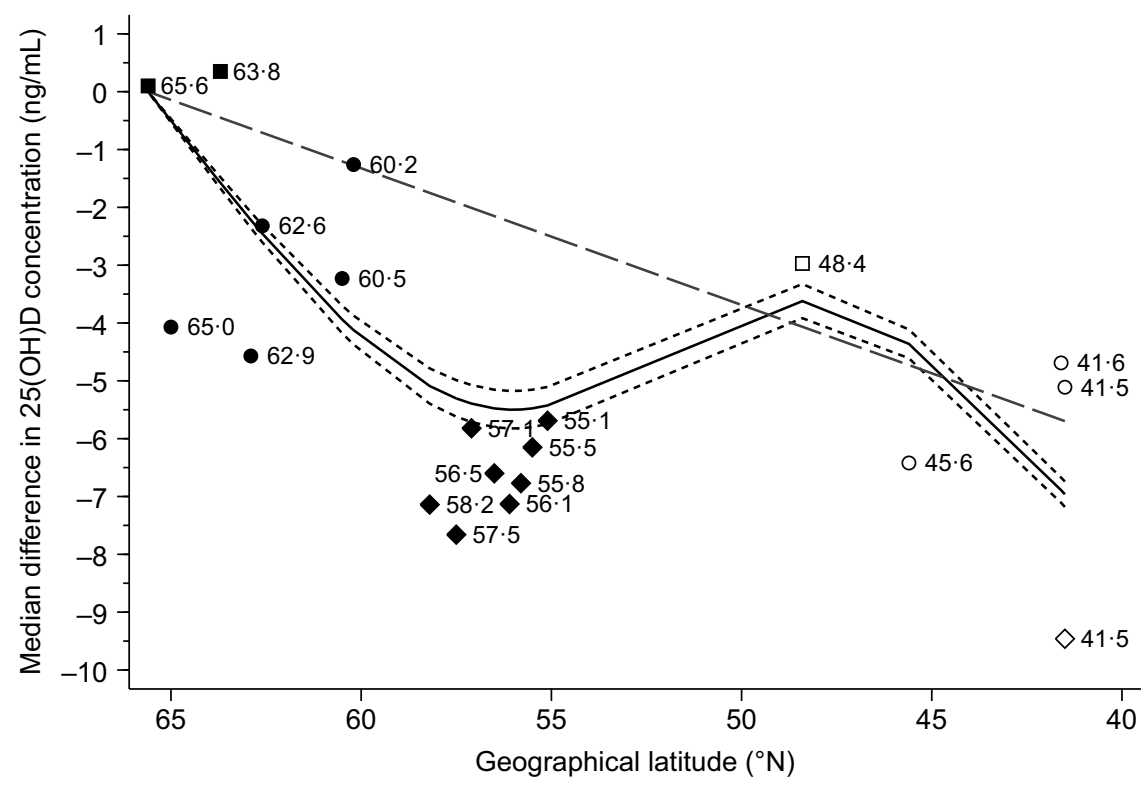

Fig. 4. Differences in 25-hydroxyvitamin $\mathrm{D}(25(\mathrm{OH}) \mathrm{D})$ status in the study population ( $n 81084$, including 84766 observations) by geographical latitude and based on multiple imputed data sets $(n 10)$. The solid line represents median differences and the short dashed lines represent $95 \% \mathrm{Cl}$ from a multivariable 4 -knot restricted cubic spline model (knots at 65.0, 55.8, $48 \cdot 4$ and $41.6^{\circ} \mathrm{N}$ ). The long dashed line represents median differences from a multivariable linear dose-response model. The symbols represent median differences from a multivariable categorical model. The numbers adjacent to the symbols represent the geographical latitude of each cohort or subcohort. The estimates were derived from quantile regression models that were adjusted for the same covariates as the multivariable model in Table 2. The comparator value was set to the northernmost subcohort at geographical latitude $65 \cdot 6^{\circ} \mathrm{N}$. घ, Sweden; $\bullet$, Finland; $\bullet$, Scotland; $\square$, Germany; O, Italy; $\diamond$, Spain.

1.0 to $11.3 \%$ ). In cohorts with more than $3 \%$ missing data, the main reason for missingness was that the blood sample volumes were too small due to previous analyses at the BiomarCaRE laboratory. However, bias by missing data should have been kept to a minimum with the use of multiple imputation techniques ${ }^{(47)}$. Fifthly, we had no data on - and could not adjust the analyses for - food and beverage consumption or use of vitamin D supplements. Sixthly, even though all of the included studies were population based in design, we cannot with certainty say that our findings are generalisable to populations outside of the recruitment areas or to the current point in time (especially since the Swedish and Finnish food-fortification policies have changed in recent years). A final limitation was that the $25(\mathrm{OH}) \mathrm{D}$ status was estimated with a 1-step immunoassay (Abbott ARCHITECT) and not a HPLC-MS/MS calibrated to a standard reference measurement procedure ${ }^{(32)}$. Our research group has previously validated the Abbott ARCHITECT against a HPLCMS/MS (traceable to the National Institute of Standards and Technology's Standard Reference Material 972) in a subgroup of the MONICA Northern Sweden cohort ${ }^{(30,31)}$, and we observed a good correlation (in terms of rank, $r=0 \cdot 82-0 \cdot 91$ ) but a general underestimation (on average $8.4 \mathrm{ng} / \mathrm{ml}$ ) of $25(\mathrm{OH}) \mathrm{D}$ concentrations. As such, the absolute percentile values in our study should be interpreted with caution and not used for the classification of vitamin D deficiency ${ }^{(12)}$ (to do so, a Vitamin D Standardisation Program protocol had been required $\left.{ }^{(15)}\right)$. However, due to the harmonised measurement, there is no reason to suspect a substantial variability in the underestimation of $25(\mathrm{OH}) \mathrm{D}$ status by country or cohort, meaning that the relative differences in percentile values should be valid.
In conclusion, in the largest study to date on the association between geographical latitude and 25(OH)D status in Europe, we confirmed the previous observation of a north-to-south gradient, with higher percentile values among north-Europeans than south-Europeans. These findings indicate that other factors are as, if not more, important as sunlight for 25(OH)D status in today's European society. Future studies are needed to understand the underlying reasons for a north-to-south gradient of $25(\mathrm{OH}) \mathrm{D}$ status in Europe.

\section{Acknowledgements}

The BiomarCaRE laboratory in Hamburg (previously in Mainz), Germany, is directed by S. B. and headed by T. Z., whose team carried out the $25(\mathrm{OH}) \mathrm{D}$ measurements. The MORGAM/ BiomarCaRE Data Centre in Helsinki, Finland, is headed by K. $\mathrm{K}$., whose team handled and harmonised the data between the included cohorts and the BiomarCaRE laboratory.

The BiomarCaRE project was funded by the European Union (EU) Seventh Framework Programme (FP7; 2007-2013) under grant agreement no. HEALTH-F2-2011-278913. The MORGAM Data Centre has also been sustained by recent funding from the EU FP7 project CHANCES (no. HEALTH-F3-2010-242244) and the EU Horizon 2020 projects euCanSHare (no. 825903) and AFFECT-EU (no. 847770). Parts of the 25(OH)D measurements were funded by the Medical Research Council London (G0601463, no. 80983: Biomarkers in the MORGAM Populations). The KORA study was initiated and financed by the Helmholtz Zentrum München and also supported within 
the Munich Center of Health Sciences, Ludwig-MaximiliansUniversität, as part of the LMUinnovativ. The MONICACatalonia study was financed by the Institute of Health Studies, Catalan Department of Health. The SHHEC study was financed by the Scottish Health Department Chief Scientist Office, the British Heart Foundation and the FP Fleming Trust. V. O., M. E. and S. S. Ö. were supported by grants from: (1) the County Councils of Norrbotten and Västerbotten, (2) the Piteå Älvdals Hospital Foundation, (3) the Joint Committee of County Councils in northern Sweden and (4) Umeå University, Umeå, Sweden. V. S. was supported by grants from the Finnish Foundation for Cardiovascular Research.

The authors' responsibilities were as follows-V. S., S. S. Ö., M. E., H. T. P., B. T., M. M. F., L. I., L. P., C. D. and S. S. A. acquired the original data; V. O. and S. S. Ö. acquired the derived data; J. R. prepared the derived data and advised on its use and interpretation; V. O. performed the statistical analyses; V. O., M. E. and S. S. Ö. interpreted the results and drafted the manuscript; and V. O. and S. S. Ö. primary responsible for the final content. All authors reviewed and revised the manuscript, approved the final version of the manuscript and participated in the study design.

Abbott Diagnostics provided test reagents for the 25(OH)D measurements within the frame of the BiomarCaRE project. Abbott Diagnostics had no role in the study design, data collection, blood sample and data analysis, decision to publish or preparation of the manuscript. S. S. Ö. has received personal fees from Actelion Pharmaceuticals Ltd (outside of the submitted work). V. S. has received honoraria from Novo Nordisk and Sanofi for consulting and has an ongoing research collaboration with Bayer Ltd (all outside of the submitted work). S. B. has received research funding from Abbott Diagnostics, Bayer, SIEMENS, Singulex and Thermo Fisher. He has also received honoraria for lectures from Abbott, Abbott Diagnostics, AstraZeneca, Bayer, AMGEN, Medtronic, Pfizer, Roche, SIEMENS Diagnostics, SIEMENS and Thermo Fisher as well as for being a member of advisory boards and for consulting for Bayer, Novartis and Thermo Fisher. The other authors have no conflicts of interest to declare.

\section{Supplementary material}

For supplementary material referred to in this article, please visit https://doi.org/10.1017/S0007114521005080

\section{References}

1. Wintermeyer E, Ihle C, Ehnert S, et al. (2016) Crucial role of vitamin D in the musculoskeletal system. Nutrients $\mathbf{8}, 319$.

2. Mondul AM, Weinstein SJ, Layne TM, et al. (2017) Vitamin D and cancer risk and mortality: state of the science, gaps, and challenges. Epidemiol Rev 39, 28-48.

3. Rai V \& Agrawal DK (2018) Role of vitamin D in cardiovascular diseases. Endocrinol Metab Clin North Am 46, 1039-1059.

4. Zhou R, Wang M, Huang H, et al. (2018) Lower vitamin D status is associated with an increased risk of ischemic stroke: a systematic review and meta-analysis. Nutrients 10, 277.

5. Lips P, Eekhoff M, van Schoor N, et al. (2017) Vitamin D and type 2 diabetes. J Steroid Biochem Mol Biol 173, 280-285.
6. Heath AK, Kim IY, Hodge AM, et al. (2019) Vitamin D status and mortality: a systematic review of observational studies. Int $J$ Environ Res Public Health 16, 383.

7. Tunstall-Pedoe H, Woodward M, Hughes M, et al. (2015) Prime mover or fellow traveller: 25-hydroxy vitamin D's seasonal variation, cardiovascular disease and death in the Scottish heart health extended cohort (SHHEC). Int J Epidemiol 44, 16021612.

8. Scragg R, Khaw KT, Toop L, et al. (2018) Monthly high-dose vitamin $\mathrm{D}$ supplementation and cancer risk: a post hoc analysis of the vitamin $\mathrm{D}$ assessment randomized clinical trial. JAMA Oncol 4, e182178.

9. Pittas AG, Dawson-Hughes B, Sheehan P, et al. (2019) Vitamin D supplementation and prevention of type 2 diabetes. NEnglJ Med 381, 520-530.

10. Barbarawi M, Kheiri B, Zayed Y, et al. (2019) Vitamin D supplementation and cardiovascular disease risks in more than 83000 individuals in 21 randomized clinical trials: a meta-analysis. JAMA Cardiol 4, 765-776.

11. Rhodes JM, Subramanian S, Laird E, et al. (2020) Editorial: low population mortality from COVID-19 in countries south of latitude $35^{\circ}$ north supports vitamin D as a factor determining severity. Aliment Pharmacol Ther 51, 1434-1437.

12. Food and Nutrition Board \& Institute of Medicine (2011) Dietary Reference Intakes for Calcium and Vitamin $D$. Washington, DC: National Academies Press.

13. Holick MF (2004) Vitamin D: importance in the prevention of cancers, type 1 diabetes, heart disease, and osteoporosis. Am J Clin Nutr 79, 362-371.

14. Webb AR, Kline L \& Holick MF (1988) Influence of season and latitude on the cutaneous synthesis of vitamin $\mathrm{D}_{3}$ : exposure to winter sunlight in Boston and Edmonton will not promote vitamin $\mathrm{D}_{3}$ synthesis in human skin. J Clin Endocrinol Metab 67, 373-378.

15. Durazo-Arvizu RA, Tian L, Brooks SPJ, et al. (2017) The vitamin D standardization program (VDSP) manual for retrospective laboratory standardization of serum 25 -hydroxyvitamin D data. $J$ AOAC Int 100, 1234-1243.

16. van der Wielen RP, Löwik MR, van den Berg H, et al. (1995) Serum vitamin D concentrations among elderly people in Europe. Lancet 346, 207-210.

17. Lips P, Duong T, Oleksik A, et al. (2001) A global study of vitamin D status and parathyroid function in postmenopausal women with osteoporosis: baseline data from the multiple outcomes of raloxifene evaluation clinical trial. J Clin Endocrinol Metab 86, 1212-1221.

18. Lips P, Hosking D, Lippuner K, et al. (2006) The prevalence of vitamin $\mathrm{D}$ inadequacy amongst women with osteoporosis: an international epidemiological investigation. J Intern Med 260, 245-254.

19. Kuchuk NO, van Schoor NM, Pluijm SM, et al. (2009) Vitamin D status, parathyroid function, bone turnover, and BMD in postmenopausal women with osteoporosis: global perspective. J Bone Miner Res 24, 693-701.

20. Deleskog A, Piksasova O, Silveira A, et al. (2013) Serum 25-hydroxyvitamin D concentration in subclinical carotid atherosclerosis. Arterioscler Thromb Vasc Biol 33, 2633-2638.

21. Cashman KD, Dowling KG, Škrabáková Z, et al. (2016) Vitamin D deficiency in Europe: pandemic? Am J Clin Nutr 103, 1033-1044.

22. Casey C, Woodside JV, McGinty A, et al. (2019) Factors associated with serum 25-hydroxyvitamin D concentrations in older people in Europe: the EUREYE study. Eur J Clin Nutr 73, 319-328.

23. Zheng JS, Imamura F, Sharp SJ, et al. (2019) Association of plasma vitamin D metabolites with incident type 2 diabetes: EPIC-InterAct case-cohort study. J Clin Endocrinol Metab 104, 1293-1303. 
24. Zeller T, Hughes M, Tuovinen T, et al. (2014) BiomarCaRE: rationale and design of the European BiomarCaRE project including 300,000 participants from 13 European countries. Eur J Epidemiol 29, 777-790.

25. Kulathinal S, Niemelä M, Niiranen T, et al. (2014) Description of MORGAM Cohorts: MORGAM Project E-Publications. http://www.thl.fi/publications/morgam/cohorts/ (accessed December 2020).

26. Evans A, Salomaa V, Kulathinal S, et al. (2005) MORGAM (an international pooling of cardiovascular cohorts). Int $J$ Epidemiol 34, 21-27.

27. von Elm E, Altman DG, Egger M, et al. (2007) Strengthening the reporting of observational studies in epidemiology (STROBE) statement: guidelines for reporting observational studies. BMJ 335, 806-808.

28. Cavalier E, Lukas P, Bekaert AC, et al. (2017) Analytical and clinical validation of the new Abbot Architect 25(OH)D assay: fit for purpose? Clin Chem Lab Med 55, 378-384.

29. Colak A, Toprak B, Dogan N, et al. (2013) Effect of sample type, centrifugation and storage conditions on vitamin D concentration. Biochem Med 23, 321-325.

30. Summerhays E, Eliasson M, Lundqvist R, et al. (2019) Time trends of vitamin D concentrations in northern Sweden between 1986 and 2014: a population-based cross-sectional study. Eur J Nutr 59, 3037-3044.

31. Ramnemark A, Norberg M, Pettersson-Kymmer U, et al. (2015) Adequate vitamin D levels in a Swedish population living above latitude $63^{\circ} \mathrm{N}$ : the 2009 Northern Sweden MONICA study. J Circumpolar Health 74, 27963.

32. Sempos CT \& Binkley N (2020) 25-Hydroxyvitamin D assay standardisation and vitamin D guidelines paralysis. Public Health Nutr 23, 1153-1164.

33. White IR, Royston P \& Wood AM (2011) Multiple imputation using chained equations: issues and guidance for practice. Stat Med 30, 377-399.

34. Orsini N \& Greenland S (2011) A procedure to tabulate and plot results after flexible modeling of a quantitative covariate. Stata J 11, 1-29.

35. Jenab M, Salvini S, van Gils CH, et al. (2009) Dietary intakes of retinol, beta-carotene, vitamin D and vitamin $\mathrm{E}$ in the European prospective investigation into cancer and nutrition cohort. EurJ Clin Nutr 63, Suppl. 4, S150-S178.
36. Jääskeläinen T, Itkonen ST, Lundqvist A, et al. (2017) The positive impact of general vitamin $\mathrm{D}$ food fortification policy on vitamin $\mathrm{D}$ status in a representative adult Finnish population: evidence from an 11-years follow-up based on standardized 25-hydroxyvitamin D data. Am J Clin Nutr 105, 1512-1520.

37. Flynn A, Hirvonen T, Mensink GBM, et al. (2009) Intake of selected nutrients from foods, from fortification and from supplements in various European countries. Food Nutr Res 53, 5-10.

38. Skeie G, Braaten T, Hjartåker A, et al. (2009) Use of dietary supplements in the European prospective investigation into cancer and nutrition calibration study. Eur J Clin Nutr 63, Suppl. 4, S226-S238.

39. Schleicher RL, Sternberg MR, Lacher DA, et al. (2016) The vitamin D status of the US population from 1988 to 2010 using standardized serum concentrations of 25-hydroxyvitamin D shows recent modest increases. Am J Clin Nutr 104, 454-461.

40. Binkley N, Krueger D, Cowgill CS, et al. (2004) Assay variation confounds the diagnosis of hypovitaminosis $\mathrm{D}$ : a call for standardization. J Clin Endocrinol Metab 89, 3152-3157.

41. Lai JKC, Lucas RM, Banks B, et al. (2012) Variability in vitamin D assays impairs clinical assessment of vitamin D status. Intern Med J 42, 43-50.

42. Carter GD (2012) 25-Hydroxyvitamin D: a difficult analyte. Clin Chem 58, 486-488.

43. Wielders JPM \& Wijnberg FA (2009) Preanalytic stability of $25(\mathrm{OH})$-vitamin $\mathrm{D}_{3}$ in human blood or serum at room temperature: solid as a rock. Clin Chem 55, 1584-1585.

44. Agborsangaya C, Toriola AT, Grankvist K, et al. (2010) The effects of storage time and sampling season on the stability of serum 25-hydroxy vitamin D and androstenedione. Nutr Cancer 62, 51-57.

45. Antoniucci DM, Black DM \& Sellmeyer DE (2005) Serum 25-hydroxyvitamin $\mathrm{D}$ is unaffected by multiple freeze-thaw cycles. Clin Chem 51, 258-261.

46. Klingberg E, Oleröd G, Konar K, et al. (2015) Seasonal variations in serum 25 -hydroxy vitamin D levels in a Swedish cohort. Endocrine 49, 800-808.

47. Knol MJ, Janssen KJ, Donders AR, et al. (2010) Unpredictable bias when using the missing indicator method or complete case analysis for missing confounder values: an empirical example. J Clin Epidemiol 63, 728-736. 